\title{
Skeletal Muscle Capillary Density and Fiber Type Are Possible Determinants of In Vivo Insulin Resistance in Man
}

\author{
Stephen Lillioja, Andrew A. Young, Carol L. Culter,* John L. Ivy, * William G. H. Abbott, Joanna K. Zawadzki, \\ Hannele Yki-Järvinen, Laurent Christin, Timothy W. Secomb, ${ }^{\ddagger}$ and Clifton Bogardus \\ Clinical Diabetes and Nutrition Section, National Institute of Diabetes and Digestive and Kidney Diseases, National Institutes of Health, \\ Phoenix, Arizona 85016; *Department of Physical Education, University of Texas, Austin, Texas 78712; and ${ }^{\ddagger}$ Department of Physiology, \\ University of Arizona, Tucson, Arizona 85721
}

\begin{abstract}
We have compared the capillary density and muscle fiber type of musculus vastus lateralis with in vivo insulin action determined by the euglycemic clamp ( $M$ value) in 23 Caucasians and 41 Pima Indian nondiabetic men. $M$ value was significantly correlated with capillary density $(r=0.63 ; P \leq 0.0001)$, percent type I fibers $(r=0.29 ; P<0.02)$, and percent type 2B fibers $(r$ $=-0.38 ; P<0.003)$. Fasting plasma glucose and insulin concentrations were significantly negatively correlated with capillary density $(r=-0.46, P \leq 0.0001 ; r=-0.47, P \leq 0.0001$, respectively). Waist circumference/thigh circumference ratio was correlated with percent type 1 fibers $(r=-0.39 ; P<0.002)$. These results suggest that diffusion distance from capillary to muscle cells or some associated biochemical change, and fiber type, could play a role in determining in vivo insulin action. The association of muscle fiber type with body fat distribution may indicate that central obesity is only one aspect of a more generalized metabolic syndrome. The data may provide at least a partial explanation for the insulin resistance associated with obesity and for the altered kinetics of insulin action in the obese.
\end{abstract}

\section{Introduction}

There is a wide range of insulin action in subjects with normal glucose tolerance (1), and furthermore the degree of impairment of insulin action in the most insulin-resistant nondiabetic subjects is as severe as that in overtly diabetic subjects $(2,3)$. Recent evidence suggests that much of an oral or intravenous glucose load is disposed of in skeletal muscle and stored $(4,5)$, and skeletal muscle therefore is likely to be the site of this in vivo insulin resistance. To date no definite explanation for the association of in vivo insulin resistance and obesity has become available. Nevertheless it is clear that insulin action in muscle could be determined by defects at a whole series of steps from the insulin receptor onwards. Lingarde et al. and Lithell et al. have provided evidence that morphological changes in muscle, particularly the size of muscle cells and the capillary supply to muscle, are associated with changes in fasting insulin concentrations and glucose tolerance $(6,7)$. This has raised the possibility that in addition to cellular biochemical defects the arrangement of capillaries and muscle fibers could also influence insulin ac-

Address all correspondence to Dr. Stephen Lillioja, Clinical Diabetes and Nutrition Section, NIDDK, NIH, 4212 N. 16th St., Room 541, Phoenix, AZ 85016.

Received for publication 29 September 1986 and in revised form 2 April 1987.

The Journal of Clinical Investigation, Inc.

Volume 80, August 1987, 415-424 tion. We now provide direct measurements of insulin action using the euglycemic clamp method and muscle morphology. In the current study we have compared in vivo insulin action with skeletal muscle morphology in 23 Caucasian and 41 Pima Indian men to test the hypothesis that impaired insulin action may be related to alterations in skeletal muscle function that are associated with altered skeletal muscle morphology.

\section{Methods}

Study subjects. The current studies were conducted in the Clinical Diabetes and Nutrition Section of the National Institute of Diabetes, Digestive and Kidney Diseases, National Institutes of Health, Phoenix, AZ. All subjects were in good health as assessed with a medical history, physical examination, and routine hematological, chemical, and urine tests. No subjects had diabetes mellitus and only one subject, a Caucasian, had impaired glucose tolerance (8) (fasting glucose, $98 \mathrm{mg} / \mathrm{dl} ; 1 \mathrm{~h}$ glucose, $207 \mathrm{mg} / \mathrm{dl} ; 2 \mathrm{~h}$ glucose, $140 \mathrm{mg} / \mathrm{dl}$ ). All subjects gave written informed consent, and the studies were approved by the ethics committees of the National Institutes of Health and the Indian Health Service, and by the Gila River Indian Community. Clinical data for the subjects were shown in Table I. Subjects were fed a weight maintenance diet (50\% carbohydrate, $30 \%$ fat, and $20 \%$ protein). Caloric requirements were predicted from body weight or fat-free mass after it was measured. Calories in the diet were adjusted according to fasting nude weight measured each morning. Body composition was determined by underwater weighing (9) with simultaneous determination of residual lung volume. Percent fat, calculated according to Keys and Brozek (10), was used to calculate fat-free mass (FFM). ${ }^{1}$ Glucose uptake and maximal oxygen uptake rates were divided by FFM to adjust for variations in metabolic body size among individuals.

Experimental protocol. Each subject stayed on the research unit for 8-15 d. On the fourth or subsequent day of their stay an oral glucose tolerance test was performed (8). On the seventh or subsequent day a euglycemic clamp was performed. An assessment of maximum oxygen uptake $\left(\mathrm{VO}_{2} \max \right)$ was performed on the last day of the hospital stay. During the hospital stay a biopsy was obtained from musculus vastus lateralis. Fasting glucoses are the means of values obtained in duplicate on three mornings. Fasting insulins are means of samples obtained at the same time as the glucoses plus duplicate samples collected before the euglycemic clamp.

Muscle biopsy. A biopsy of musculus vastus lateralis was obtained via an 8-mm incision through skin and fascia 1-2 inches from the midline in the midlateral thigh using a Bergstrom needle. The patient was supine with the lower limb slightly internally rotated, and the biopsy needle was directed vertically. The specimen was examined under a low-powered microscope to determine muscle fiber orientation. The specimen was

1. Abbreviations used in this paper: $\mathrm{CV}$, coefficient of variation; $\mathrm{EGPR}$, endogenous glucose production rate; FFM, fat-free mass; $\max M$, glucose uptake at maximally stimulating insulin concentration; $\mathrm{Ra}$, appearance rate; submax $M$, glucose uptake at submaximally stimulating insulin concentrations; $\mathrm{VO}_{2}$ max, maximum oxygen uptake; $\mathrm{W} / \mathrm{T}$, waist circumference to thigh circumference ratio. 
Table I. Clinical Data

\begin{tabular}{|c|c|c|}
\hline & Mean \pm SD & $\begin{array}{l}\text { Minimum and } \\
\text { maximum value }\end{array}$ \\
\hline Age $(y r)$ & $27 \pm 6$ & $18-41$ \\
\hline Weight $(k g)$ & $95.1 \pm 30.9$ & $49.4-176.3$ \\
\hline Height $(m)$ & $1.72 \pm 0.07$ & $1.59-1.91$ \\
\hline Waist/thigh & $1.60 \pm 0.16$ & $1.31-2.03$ \\
\hline Body fat $(\%)^{*}$ & $25 \pm 10$ & $5-48$ \\
\hline Fasting glucose $(m g / d l)^{\ddagger}$ & $96 \pm 7$ & $82-116$ \\
\hline $2 \mathrm{~h}$ glucose $(\mathrm{OGTT})(\mathrm{mg} / \mathrm{dl})$ & $119 \pm 23$ & $75-178$ \\
\hline Fasting insulin $(\mu U / m l)^{8}$ & $28 \pm 5$ & $9-69$ \\
\hline $2 \mathrm{~h}$ insulin (OGTT) $(\mu U / m l)$ & $154 \pm 184$ & $19-1191$ \\
\hline Submax $M(m g / k g F F M \cdot m i n)$ & $4.29 \pm 2.13$ & $1.77-9.99$ \\
\hline $\operatorname{Max} \mathrm{M}(m g / k g F F M \cdot \min )$ & $11.66 \pm 3.15$ & $6.00-18.30$ \\
\hline $\mathrm{VO}_{2} \max (\mathrm{ml} / \mathrm{kg} F F M \cdot \min )^{\prime \prime}$ & $51.5 \pm 8.6$ & $33.8-74.5$ \\
\hline Fiber area $\left(\mu m^{2}\right)$ & $6146 \pm 1700$ & $3587-10618$ \\
\hline Capillaries/muscle fiber & $1.60 \pm 0.30$ & $0.87-2.30$ \\
\hline No. capillaries around each fiber & $4.3 \pm 0.7$ & $2.4-6.2$ \\
\hline Capillaries $/ \mathrm{mm}^{2}$ & $275 \pm 64$ & $161-426$ \\
\hline \% Type 1 & $46 \pm 11$ & $23-74$ \\
\hline$\%$ Type $2 \mathrm{a}$ & $27 \pm 12$ & $4-54$ \\
\hline$\%$ Type $2 b$ & $27 \pm 15$ & $0-61$ \\
\hline
\end{tabular}

Muscle fiber data refer to musculus vastus lateralis.

* From underwater weighing.

¥ Drawn in duplicate on three separate days.

Drawn in duplicate on four separate days.

$\| n=56$.

then mounted in an imbedding matrix (OCT compound, Miles Laboratories, Naperville, IL) and frozen in isopentane (Aldrich Chemical Co., Milwaukee, WI) cooled to its freezing point with liquid $\mathrm{N}_{2}$. All muscle analyses were performed at the University of Texas.

Euglycemic clamp (submax $M, \max M$ ). The euglycemic clamp was performed by a modification of the method of DeFronzo et al. (11) after a 13-14-h overnight fast. At $0600 \mathrm{~h}$, after voiding, an intravenous catheter was placed in an antecubital vein for infusion of insulin, glucose, and $3-\left[{ }^{3} \mathrm{H}\right]$ glucose. Another catheter was placed retrograde in a dorsal vein of the contralateral hand for blood withdrawal. The hand was kept in a warming box at $70^{\circ} \mathrm{C}$. A primed continuous infusion of $3-\left[{ }^{3} \mathrm{H}\right]$ glucose was then begun and continued throughout the first insulin infusion period. After $2 \mathrm{~h}$ of $3-\left[{ }^{3} \mathrm{H}\right]$ glucose infusion, four plasma samples were obtained during a 20 -min period for $3-\left[{ }^{3} \mathrm{H}\right]$ glucose specific activity determinations. At the end of this collection period a primed continuous infusion of purified pork insulin (Velosulin; Nordisk USA, Bethesda, MD) (40 mU/ $\mathrm{m}^{2}$ per min) (submax $\mathrm{M}$ ) was started. 5 min after the start of the insulin, a variable $20 \%$ glucose infusion was begun to maintain the plasma glucose concentration at approximately the basal glucose level for the entire 100 min of hyperinsulinemia. Samples for plasma glucose concentration were obtained every $5 \mathrm{~min}$ throughout the test. Samples for $3-\left[{ }^{3} \mathrm{H}\right]$ glucose specific activity were obtained every $10 \mathrm{~min}$ from 60 to $100 \mathrm{~min} .100$ $\mathrm{min}$ after the start of the first insulin infusion, a second primed continuous infusion of insulin was commenced $\left(400 \mathrm{mU} / \mathrm{m}^{2}\right.$ per $\left.\min \right)(\max \mathrm{M})$ and continued for a further $100 \mathrm{~min}$. Samples were drawn for measurement of insulin levels at 15 and $8 \mathrm{~min}$ before the start of the insulin infusion, and at $85,95,185$, and 195 min afterwards. Mean ( \pm SE) of glucose and insulin levels during the clamp were: lower insulin infusion (submax M), glucose $95 \pm 0.6 \mathrm{mg} / 100 \mathrm{ml}$ (mean coefficient of variation [CV] $2.4 \pm 0.1 \%$ ), insulin $119 \pm 4.7 \mu \mathrm{U} / \mathrm{ml}$ (mean CV 4.6 $\pm 0.6 \%$ ); higher insulin $(\max M)$ infusion, glucose $95 \pm 0.5 \mathrm{mg} / 100 \mathrm{ml}$ (mean CV $3.1 \pm 0.2 \%$ ), insulin $2,027 \pm 75 \mu \mathrm{U} / \mathrm{ml}(\mathrm{CV} 7.2 \pm 1.9 \%)$.

The appearance rate $(\mathrm{Ra})$ of glucose in the plasma was calculated from the plasma $3-\left[{ }^{3} \mathrm{H}\right]$ glucose specific activities using the equations of
Steel (12). During the euglycemic clamp the endogenous glucose production rate (EGPR) equals the difference between exogenous glucose infusion rate and $R$ a calculated using Steele's non-steady state equations (EGPR $=\mathbf{R a}-$ exogenous glucose infusion rate). When Ra equals exogenous glucose infusion rate, EGPR is assumed to be completely suppressed so that the total glucose disposal rate equals the exogenous glucose infusion rate. These data were calculated for each 20-min interval in the 60-100 min period of the euglycemic clamp and then averaged to calculate the total glucose uptake. Data were similarly calculated from 160 to $200 \mathrm{~min}$ but without the tritiated glucose measurements. Insulin clearance rates have been shown to vary among individuals $(13,14)$. In this report those subjects with the lower glucose uptake rates had higher insulin concentrations at each insulin infusion level.

$\mathrm{VO}_{2}$ max determination. A graded exercise test was performed the day after the euglycemic clamp procedure by using intermittent work bouts on a treadmill (data available on 56 subjects only). Each test was started at 0-5 degrees elevation and involved walking at $1.5 \mathrm{mph}$. Elevation and speed of the treadmill were gradually increased. After $4 \mathrm{~min}$ at each work level, the subject sat down until the heart rate was $<120$ beats per minute (bpm), and he had subjectively recovered. The test continued until the patient was subjectively exhausted, the heart rate reached $200 \mathrm{bpm}$, or there was no further increase in oxygen uptake $\left(\mathrm{VO}_{2}\right)$ (see references 15,16$) . \mathrm{VO}_{2}$ was determined during the last $30 \mathrm{~s}$ to $1 \mathrm{~min}$ of each work bout. The subject was connected to a low-resistance mouthpiece of a "J" value (Warren E. Collins, Inc., Braintree, MA).

After 0.5-1 min of adaptation the expired air was collected in a 120liter Tissot spirometer (Warren E. Collins, Inc.). During the collection period a sample of expired air was continuously drawn and analyzed for oxygen and carbon dioxide. The average fraction of $\mathrm{O}_{2}$ and $\mathrm{CO}_{2}$, minute ventilation oxygen uptake, $\mathrm{CO}_{2}$ production, and respiratory quotient were calculated by an on-line Hewlett Packard 85 computer and printed out at the end of each collection. $\mathrm{VO}_{2}$ max was determined as the highest $\mathrm{VO}_{2}$ value recorded during the exercise test.

Analytical methods. Plasma glucose concentration was measured by the glucose oxidase method using a glucose analyzer (Beckman Instruments, Inc., Fullerton, CA). Plasma insulin concentration was determined by the Herbert modification (17) of the radioimmunoassay of Berson and Yalow (18). The tritiated glucose specific activity in blood samples was measured, as described previously by others (19), using perchloric acid to precipitate plasma proteins.

Biopsy specimens were mounted in an imbedding matrix (OCT) and frozen in isopentane cooled to its freezing point with liquid $\mathrm{N}_{2}$. Tissue slices $12 \mu \mathrm{m}$ thick were cut in a cryosat set at $-20^{\circ} \mathrm{C}$ and used for histochemical analysis. Sections were fixed, treated with a $1 \%$ amylase solution, and stained with periodic acid-Schiff reagent to visualize capillaries $(20)$. The stained sections were analyzed by magnifying $(\times 296)$ and projecting numerous artifact-free $0.25 \mathrm{~mm}^{2}$ areas onto a screen (Fig. 1). The number of capillaries within the known area were counted and capillary density (cap/ $/ \mathrm{mm}^{2}$ ) determined. Fiber type analysis was also performed. Sections were stained for their myosin ATP-ase activity according to Padykula and Herman (24), after preincubation at pH 4.30, 4.54, and 9.60. The fibers were classified as either type I, IIa, or IIb according to Dubowitz and Brooke (25).

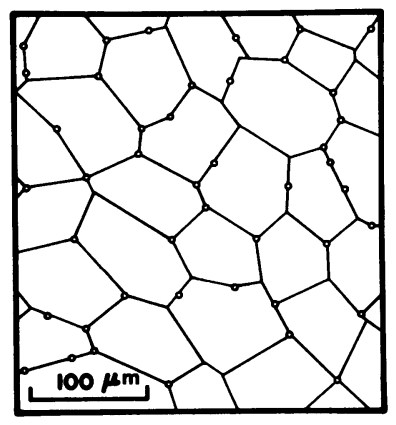

Figure 1. Cross-section of skeletal muscle copied from projected image of microscopic slide used in sample analysis (see Methods). For this subject, mean fiber area $=4,250 \mu \mathrm{m}^{2}$, capillary density $=399 \mathrm{caps} / \mathrm{mm}^{2}$, capillaries per fiber $=1.68$, and capillaries around each fiber $=4.7$. Capillaries and muscle fibers run parallel to each other, perpendicular to the page (21-23). 
Statistical methods. All statistical calculations, including calculations of means, correlations, multiple regression, and multivariate regression (partial regression) analyses were performed using standard programs of the SAS Institute (Statistical Analysis System, Cary, NC). Correlations are Pearson-product moment correlations. Log transformations of fasting insulin and fiber area were used to decrease unequal variances in the regressions, and a log transformation of submax $M$ was used to improve linearity and normalize the distribution.

\section{Results}

In vivo insulin action at submaximal and maximal stimulating insulin infusion rates (submax $\mathbf{M}$ and $\max \mathbf{M}$ ) was significantly correlated with the number of capillaries per unit area in skeletal muscle cross-sections (caps $/ \mathrm{mm}^{2}$; capillary density) $(r=0.63$, $P \leq 0.0001 ; r=0.47, P \leq 0.0001$, respectively) (Fig. 2). Submax $M$ (Fig. 3) and max M (Fig. 4) were also correlated with skeletal muscle fiber types (for percent type I fibers, $r=0.29, P<0.02$; $r=0.29, P<0.03$, respectively; for percent type 2B fibers, $r$ $=-0.38, P<0.003 ; r=-0.32, P<0.01$, respectively). The relationship between submax $M$ and percent type $2 B$ fibers was significant, independent of capillary density $(r=-0.28, P$ $<0.03$ ); the relationship of $\max M$ and percent type $2 B$ was weakly significant, independent of capillary density $(r=-0.23$, $P=0.06$ ). Both measures of insulin action were negatively correlated with degree of obesity (percent fat) and waist circumference/thigh circumference ratio (W/T) (Table II). Fasting plasma glucose (Fig. 5) and fasting plasma insulin (Fig. 6) concentrations were negatively correlated with capillary density $(r=-0.46, P$ $\leq 0.0001 ; r=-0.47, P \leq 0.0001)$.

Using multivariate regression submax $M$ was correlated with capillary density independent of percent fat or W/T (Tables III and IV) ( $r=0.36, P<0.004 ; r=0.37, P<0.003$, respectively). Max $\mathrm{M}$ was correlated with capillary density independent of percent fat $(r=0.27, P<0.04)$ but not independent of W/T $(r$ $=0.19, P=0.13)$. The relationships between insulin action and fiber type were no longer significant when either percent fat or $\mathrm{W} / \mathrm{T}$ were taken into account. Percent fat and $\mathrm{W} / \mathrm{T}$ remain significantly correlated with insulin action independent of capillary density (Table V) $(r=-0.57, P \leq 0.0001 ; r=-0.50, P \leq 0.0001$ for submax M) $(r=-0.29, P<0.03 ; r=-0.42, P<0.001$ for $\max M)$. Using multiple regression capillary density, percent fat, or $\mathrm{W} / \mathrm{T}$ alone explained 40,53 , and $48 \%$, respectively, of the variance of submax M. Capillary density and percent fat together or capillary density and $\mathrm{W} / \mathrm{T}$ together explained 59 and $55 \%$ of

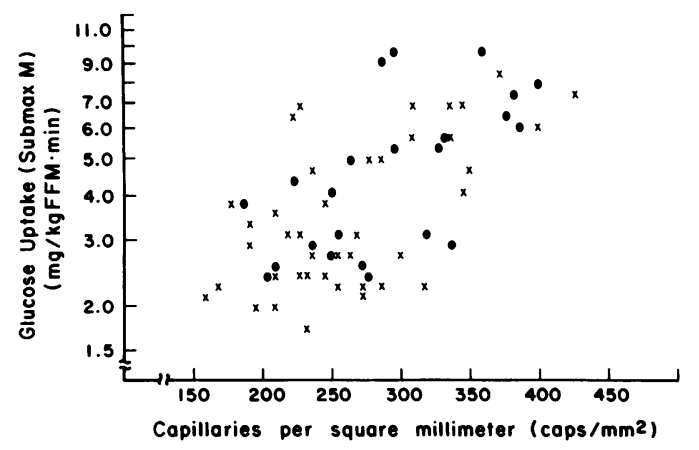

Figure 2. Relationship of glucose uptake at submaximal stimulating insulin concentrations and capillary density. The relationship is nonlinear and therefore plotted on a $\log$ scale for $M(r=0.63, P$ $\leq 0.0001)$. ( $x$ ) Indians; (๑) Caucasians.

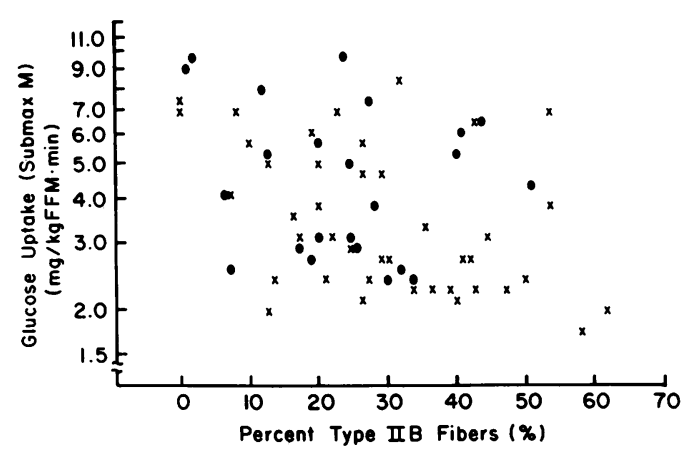

Figure 3. Correlation of submax $\mathrm{M}$ and percent type 2B fibers ( $r$ $=-0.38, P<0.003)$. ( $x$ ) Indians; (๑) Caucasians.

the variance of submax $M$, respectively. Equivalent values for $\max M$ were 22, 24, 33, 29, and $36 \%$.

Capillary density was significantly lower in the most obese $(r=-0.59, P \leq 0.0001$ ) (Fig. 7). This was partially explained by the observations that while muscle fiber cross-sectional area was greater in the most obese $(r=0.39, P<0.002)$ (Fig. 8), the number of capillaries for each muscle fiber was no greater $(r$ $=-0.17, P=0.2$ ). However, the most obese had lower capillary densities even when fiber area was taken into account $(r=-0.48$, $P \leq 0.0001$ ) by multivariate regression.

Degree of obesity was significantly correlated with muscle fiber types $(r=-0.32, P<0.01 ; r=0.32, P<0.02$ for percent type 1 and type 2B, respectively). W/T as a measure of body fat distribution was even more closely related to capillary density (Fig. 9), percent type 1 fibers (Fig. 10) and percent type 2B fibers $(r=-0.60, P \leq 0.0001 ; r=-0.39, P<0.002 ; r=0.40, P$ $<0.002$, respectively). The $r^{2}$ of the relationship of percent type 1 fibers and percent type $2 b$ fibers to percent fat was 0.10 and 0.10 , respectively. The $r^{2}$ for fiber types and $\mathrm{W} / \mathrm{T}$ were 0.16 and 0.16 , respectively. When both percent fat and $W / T$ were used as regressors in the same model the $r^{2}$ values were 0.16 and 0.16 for percent type 1 and $2 b$ fibers, i.e., any contribution percent fat made to the fiber type variance could be known if the $W / T$ was known. The relationships of capillary density and fiber type with $\mathrm{W} / \mathrm{T}$ were still significant or almost so when the degree of obesity was taken into account (Table III) $(r=-0.29, P<0.03$; $r=-0.24, P=0.06 ; r=0.25, P<0.05$ for caps $/ \mathrm{mm}^{2}$, percent type 1 , percent type $2 B$, respectively).

$\mathrm{VO}_{2} \max$ was correlated with capillary density $(r=0.32, P$ $<0.02)$, percent type 1 fibers $(r=0.29, P<0.05)$ and percent type 2B fibers $(r=-0.42, P<0.002)$ and also with the $M$ values

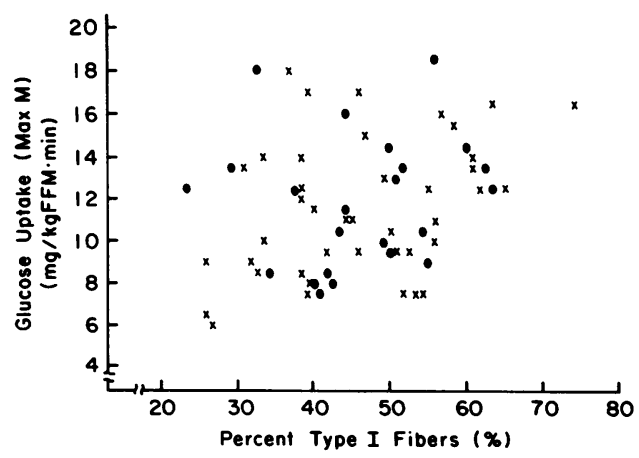

Figure 4. Correlation of $\max M$ and percent type 1 fibers $(r=0.29, P$ $<0.03)$. $(x)$ Indians; $(\bullet)$ Caucasians. 
Table II. Simple Correlations: Correlation Coefficients/P Values

\begin{tabular}{|c|c|c|c|c|c|c|c|c|c|c|}
\hline & $\begin{array}{l}\text { Submax } \\
\text { M }\end{array}$ & $\operatorname{Max} M$ & $\begin{array}{l}\text { Fasting } \\
\text { glucose* }\end{array}$ & $\begin{array}{l}\text { Fasting } \\
\text { insulin }^{\ddagger}\end{array}$ & \% Type 1 & $\begin{array}{l}\% \text { Type } \\
2 B\end{array}$ & Fiber area & $\begin{array}{l}\text { Capillaries/ } \\
\text { fiber }\end{array}$ & $\begin{array}{l}\text { Capillaries/ } \\
\text { mm }^{2}\end{array}$ & $\begin{array}{l}\text { \% Body } \\
\text { fat }\end{array}$ \\
\hline Max M & $\begin{array}{c}0.81 \\
\leq 0.0001\end{array}$ & . & & & & & & & & \\
\hline Fasting glucose* & $\begin{array}{l}-0.51 \\
\leq 0.0001\end{array}$ & $\begin{array}{l}-0.27 \\
<0.04\end{array}$ & & & & & & & & \\
\hline Fasting insulin $\ddagger$ & $\begin{array}{l}-0.78 \\
\leq 0.0001\end{array}$ & $\begin{array}{l}-0.70 \\
\leq 0.0001\end{array}$ & $\begin{array}{c}0.54 \\
\leq 0.0001\end{array}$ & & & & & & & \\
\hline \% Type 1 & $\begin{array}{r}0.29 \\
<0.02\end{array}$ & $\begin{array}{r}0.29 \\
<0.03\end{array}$ & $\begin{array}{l}-0.11 \\
=0.4\end{array}$ & $\begin{array}{l}-0.23 \\
=0.06\end{array}$ & & & & & & \\
\hline \% Type 2B & $\begin{array}{l}-0.38 \\
<0.003\end{array}$ & $\begin{array}{l}-0.32 \\
<0.01\end{array}$ & $\begin{aligned} & 0.24 \\
= & 0.05\end{aligned}$ & $\begin{array}{r}0.31 \\
<0.02\end{array}$ & $\begin{array}{l}-0.63 \\
\leq 0.0001\end{array}$ & & & & & \\
\hline Fiber area & $\begin{array}{l}-0.49 \\
\leq 0.0001\end{array}$ & $\begin{array}{l}-0.37 \\
<0.003\end{array}$ & $\begin{array}{c}0.39 \\
<0.002\end{array}$ & $\begin{array}{c}0.42 \\
<0.0006\end{array}$ & $\begin{array}{l}-0.08 \\
=0.5\end{array}$ & $\begin{aligned} & 0.07 \\
= & 0.6\end{aligned}$ & & & & \\
\hline Capillaries/muscle fiber & $\begin{aligned} & 0.07 \\
= & 0.6\end{aligned}$ & $\begin{aligned} & 0.03 \\
= & 0.8\end{aligned}$ & $\begin{array}{l}-0.06 \\
=0.7\end{array}$ & $\begin{aligned} & 0.01 \\
= & 0.9\end{aligned}$ & $\begin{array}{r}0.34 \\
<0.01\end{array}$ & $\begin{array}{l}-0.23 \\
=0.07\end{array}$ & $\begin{array}{c}0.53 \\
\leq 0.0001\end{array}$ & & & \\
\hline Capillaries/mm ${ }^{2}$ & $\begin{array}{c}0.63 \\
\leq 0.0001\end{array}$ & $\begin{array}{c}0.47 \\
\leq 0.0001\end{array}$ & $\begin{array}{l}-0.46 \\
\leq 0.0001\end{array}$ & $\begin{array}{l}-0.47 \\
\leq 0.0001\end{array}$ & $\begin{array}{c}0.39 \\
<0.002\end{array}$ & $\begin{array}{l}-0.27 \\
<0.04\end{array}$ & $\begin{array}{l}-0.68 \\
\leq 0.0001\end{array}$ & 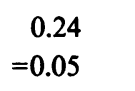 & & \\
\hline$\%$ Body fat ${ }^{8}$ & $\begin{array}{l}-0.73 \\
\leq 0.0001\end{array}$ & $\begin{array}{l}-0.49 \\
\leq 0.0001\end{array}$ & $\begin{array}{c}0.48 \\
\leq 0.0001\end{array}$ & $\begin{array}{c}0.70 \\
\leq 0.0001\end{array}$ & $\begin{array}{l}-0.32 \\
<0.01\end{array}$ & $\begin{array}{r}0.32 \\
<0.02\end{array}$ & $\begin{array}{c}0.39 \\
<0.002\end{array}$ & $\begin{array}{l}-0.17 \\
=0.2\end{array}$ & $\begin{array}{l}-0.59 \\
\leq 0.0001\end{array}$ & \\
\hline $\mathrm{W} / \mathrm{T}$ & $\begin{array}{l}-0.69 \\
\leq 0.0001\end{array}$ & $\begin{array}{l}-0.58 \\
\leq 0.0001\end{array}$ & $\begin{array}{c}0.47 \\
\leq 0.0001\end{array}$ & $\begin{array}{c}0.71 \\
\leq 0.0001\end{array}$ & $\begin{array}{l}-0.39 \\
<0.002\end{array}$ & $\begin{array}{c}0.40 \\
<0.002\end{array}$ & $\begin{array}{r}0.32 \\
<0.01\end{array}$ & $\begin{array}{l}-0.29 \\
<0.02\end{array}$ & $\begin{array}{l}-0.60 \\
\leq 0.0001\end{array}$ & $\begin{array}{c}0.78 \\
\leq 0.0001\end{array}$ \\
\hline
\end{tabular}

$n=64$. Muscle fiber data refer to musculus vastus lateralis. ${ }^{*}$ Drawn in duplicate on three separate days. ${ }^{\ddagger}$ Drawn in duplicate on four separate days. ${ }^{8}$ From underwater weighing.

( $r=0.57, P \leq 0.0001$ and $r=0.58, P \leq 0.0001$ for submax and $\max M$, respectively).

Number of capillaries per muscle fiber and number of capillaries per square millimeter (capillary density) (Fig. 11) both correlated with percentage of type 1 fibers $(r=0.34, P<0.01$; $r=0.39, P<0.002$, respectively). The correlations of both these capillary measures with percent type 2B fibers was weaker ( $r$ $=-0.23, P=0.07 ; r=-0.27, P<0.04)$.

\section{Discussion}

We have demonstrated that in vivo insulin action is significantly correlated with both the density of capillary supply to skeletal

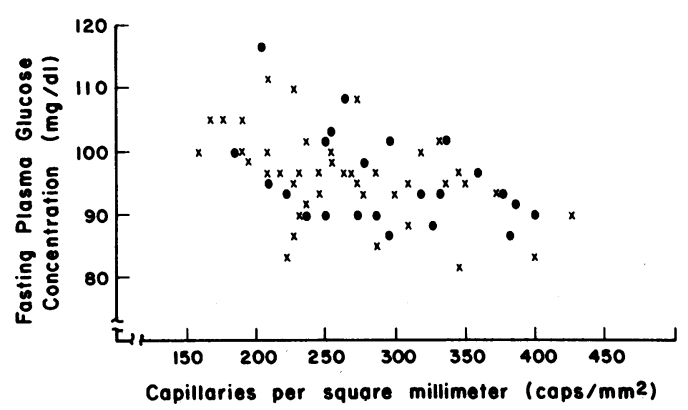

Figure 5. Relationship of fasting glucose (mean of duplicates on three different days) and capillary density $(r=-0.46, P \leq 0.0001) .(x)$ Indians; (๑) Caucasians. muscle and the histologically determined proportions of muscle fiber types. In addition, fasting plasma glucose concentrations even within the narrow range of normal values were also strongly correlated with capillary density. We also confirmed a previous report that a central distribution of obesity is associated with a higher proportion of type 2B fibers (26).

We propose that these data may be explained by some combinations of the following three mechanisms. Alterations in insulin action may occur because (a) specific biochemical changes

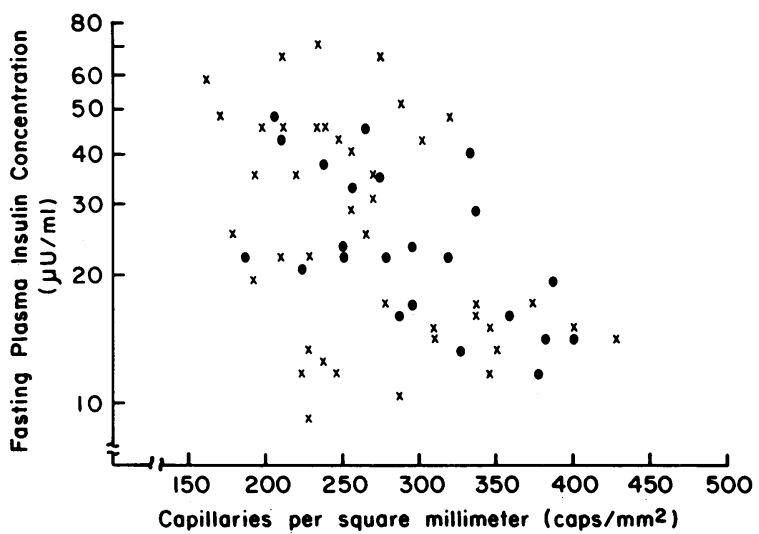

Figure 6. Relationship of fasting insulin (mean of duplicates on four different days) and capillary density $(r=-0.47, P \leq 0.0001)$. ( $x$ ) Indians; (๑) Caucasians. 
Table III. Multivariate Regression: Independent Variable Percent Fat

\begin{tabular}{|c|c|c|c|c|c|c|c|}
\hline & \multicolumn{7}{|c|}{ Partial correlation coefficients/P values } \\
\hline & Submax M & $\operatorname{Max} \mathbf{M}$ & Fasting glucose* & Fasting insulin ${ }^{\ddagger}$ & \% Type 1 & \% Type 2B & Capillaries/mm ${ }^{2}$ \\
\hline $\operatorname{Max} \mathbf{M}$ & $\begin{array}{c}0.76 \\
\leq 0.0001\end{array}$ & & & & & & \\
\hline Fasting glucose* & $\begin{array}{l}-0.26 \\
<0.04\end{array}$ & $\begin{array}{l}-0.04 \\
=0.7\end{array}$ & & & & & \\
\hline Fasting insulin ${ }^{\ddagger}$ & $\begin{array}{l}-0.55 \\
\leq 0.0001\end{array}$ & $\begin{array}{l}-0.58 \\
\leq 0.0001\end{array}$ & $\begin{array}{r}0.32 \\
<0.02\end{array}$ & & & & \\
\hline \% Type 1 & $\begin{aligned} & 0.09 \\
= & 0.5\end{aligned}$ & $\begin{array}{r}0.16 \\
=0.21\end{array}$ & $\begin{aligned} & 0.05 \\
= & 0.7\end{aligned}$ & $\begin{array}{r}0.0 \\
=0.9\end{array}$ & & & \\
\hline$\%$ Type 2B & $\begin{array}{l}-0.22 \\
=0.08\end{array}$ & $\begin{array}{l}-0.21 \\
=0.11\end{array}$ & $\begin{aligned} & 0.10 \\
= & 0.5\end{aligned}$ & $\begin{aligned} & 0.13 \\
= & 0.3\end{aligned}$ & $\begin{array}{l}-0.59 \\
\leq 0.0001\end{array}$ & & \\
\hline Capillaries/mm ${ }^{2}$ & $\begin{array}{c}0.36 \\
<0.004\end{array}$ & $\begin{array}{r}0.27 \\
<0.04\end{array}$ & $\begin{array}{l}-0.25 \\
=0.05\end{array}$ & $\begin{array}{l}-0.10 \\
=0.4\end{array}$ & $\begin{array}{r}0.25 \\
<0.05\end{array}$ & $\begin{array}{l}-0.10 \\
=0.4\end{array}$ & \\
\hline $\mathbf{W} / \mathbf{T}$ & $\begin{array}{l}-0.29 \\
<0.03\end{array}$ & $\begin{array}{l}-0.36 \\
<0.004\end{array}$ & $\begin{array}{r} \\
0.18 \\
=0.16\end{array}$ & $\begin{array}{c}0.37 \\
<0.003\end{array}$ & $\begin{array}{l}-0.24 \\
=0.06\end{array}$ & $\begin{array}{r}0.25 \\
<0.05\end{array}$ & $\begin{array}{l}-0.29 \\
<0.03\end{array}$ \\
\hline
\end{tabular}

Muscle fiber data refer to musculus vastus lateralis. * Drawn in duplicate on three separate days. ${ }^{\ddagger}$ Drawn in duplicate on four separate days.

occur in association with variations in cellular oxidative capacity (oxidative capacity being correlated with capillary supply), (b) limitations are imposed on the diffusion of insulin and perhaps glucose when capillaries are more widely spaced (c.f. 21), and (c) biochemical changes are induced in parallel with the specific twitch characteristics (fiber type) of muscle fibers (see references 27-34). Furthermore, the correlation of fiber type with insulin action may help explain the familial dependence of insulin action because fiber type appears to be genetically determined $(35,36)$.
The data may also help provide mechanisms to explain the association of obesity with insulin resistance and altered kinetics of insulin action (37-40), to explain the association of W/T with disturbances of glucose tolerance (41), and to explain some of the variation in fasting glucose concentrations within the normal range.

Muscle analyses were performed on one small muscle sample from only one skeletal muscle. Such sampling would be expected to increase the scatter in the data when comparing the muscle

Table IV. Multivariate Regression: Independent Variable Waist/Thigh

\begin{tabular}{|c|c|c|c|c|c|c|c|}
\hline & \multicolumn{7}{|c|}{ Partial correlation coefficients/P values } \\
\hline & Submax $\mathbf{M}$ & $\operatorname{Max} \mathbf{M}$ & Fasting glucose* & Fasting insulin ${ }^{*}$ & \% Type 1 & \% Type 2B & Capillaries/mm² \\
\hline Max M & $\begin{array}{c}0.69 \\
\leq 0.0001\end{array}$ & & & & & & \\
\hline Fasting glucose* & $\begin{array}{l}-0.29 \\
<0.03\end{array}$ & $\begin{array}{r} \\
0.0 \\
=1.0\end{array}$ & & & & & \\
\hline Fasting insulin ${ }^{\ddagger}$ & $\begin{array}{l}-0.57 \\
\leq 0.0001\end{array}$ & $\begin{array}{l}-0.51 \\
\leq 0.0001\end{array}$ & $\begin{array}{r}0.32 \\
<0.01\end{array}$ & & & & \\
\hline \% Type 1 & $\begin{aligned} & 0.03 \\
= & 0.8\end{aligned}$ & $\begin{aligned} & 0.08 \\
= & 0.5\end{aligned}$ & $\begin{aligned} & 0.09 \\
= & 0.5\end{aligned}$ & $\begin{aligned} & 0.07 \\
= & 0.6\end{aligned}$ & & & \\
\hline \% Type 2B & $\begin{array}{l}-0.15 \\
=0.2\end{array}$ & $\begin{array}{l}-0.13 \\
=0.3\end{array}$ & $\begin{aligned} & 0.06 \\
= & 0.7\end{aligned}$ & $\begin{aligned} & 0.04 \\
= & 0.7\end{aligned}$ & $\begin{array}{l}-0.56 \\
\leq 0.0001\end{array}$ & & \\
\hline Capillaries/mm² & $\begin{array}{c}0.37 \\
<0.003\end{array}$ & $\begin{array}{r}0.19 \\
=0.13\end{array}$ & $\begin{array}{l}-0.25 \\
<0.05\end{array}$ & $\begin{array}{l}-0.08 \\
=0.5\end{array}$ & $\begin{array}{r}0.20 \\
=0.11\end{array}$ & $\begin{array}{l}-0.04 \\
=0.8\end{array}$ & \\
\hline$\%$ Body fat ${ }^{8}$ & $\begin{array}{l}-0.43 \\
<0.0006\end{array}$ & $\begin{array}{l}-0.07 \\
=0.6\end{array}$ & $\begin{array}{r}0.21 \\
=0.10\end{array}$ & $\begin{array}{r}0.34 \\
<0.01\end{array}$ & $\begin{array}{l}-0.03 \\
=0.8\end{array}$ & $\begin{aligned} & 0.02 \\
= & 0.9\end{aligned}$ & $\begin{array}{l}-0.24 \\
=0.06\end{array}$ \\
\hline
\end{tabular}

Muscle fiber data refer to musculus vastus lateralis. * Drawn in duplicate on three separate days. ₹ Drawn in duplicate on four separate days. ${ }^{8}$ Determined from underwater weighing. 
Table V. Multivariate Regression: Independent Variable Capillaries/mm

\begin{tabular}{|c|c|c|c|c|c|c|}
\hline & \multicolumn{6}{|c|}{ Partial correlation coefficients/P values } \\
\hline & Submax M & $\operatorname{Max} \mathbf{M}$ & Fasting glucose* & Fasting insulin & \% Type 1 & \% Type 2B \\
\hline \multirow[t]{2}{*}{$\operatorname{Max} \mathbf{M}$} & 0.74 & & & & & \\
\hline & $\leq 0.0001$ & & & & & \\
\hline \multirow[t]{2}{*}{ Fasting glucose* } & -0.32 & -0.06 & & & & \\
\hline & $<0.02$ & $=0.6$ & & & & \\
\hline \multirow[t]{2}{*}{ Fasting insulin ${ }^{\ddagger}$} & -0.71 & -0.62 & 0.41 & & & \\
\hline & $\leq 0.0001$ & $\leq 0.0001$ & $<0.001$ & & & \\
\hline \multirow[t]{2}{*}{$\%$ Type 1} & 0.07 & 0.13 & 0.08 & -0.06 & & \\
\hline & $=0.6$ & $=0.3$ & $=0.5$ & $=0.6$ & & \\
\hline \multirow[t]{2}{*}{$\%$ Type 2B } & -0.28 & -0.23 & 0.13 & 0.22 & -0.60 & \\
\hline & $<0.03$ & $=0.06$ & $=0.3$ & $=0.09$ & $\leq 0.0001$ & \\
\hline \multirow[t]{2}{*}{$\%$ Body fat ${ }^{8}$} & -0.57 & -0.29 & 0.30 & 0.60 & -0.13 & 0.21 \\
\hline & $\leq 0.0001$ & $<0.03$ & $<0.02$ & $\leq 0.0001$ & $=0.3$ & $=0.10$ \\
\hline \multirow[t]{2}{*}{$\mathbf{W} / \mathbf{T}$} & -0.50 & -0.42 & 0.28 & 0.61 & -0.22 & 0.31 \\
\hline & $\leq 0.0001$ & $<0.001$ & $<0.03$ & $\leq 0.0001$ & $=0.08$ & $<0.02$ \\
\hline
\end{tabular}

Muscle fiber data refer to musculus vastus lateralis. ${ }^{*}$ Drawn in duplicate on three separate days. ${ }^{\ddagger}$ Drawn in duplicate on four separate days.

${ }^{8}$ Determined from underwater weighing.

observations with whole body observations. On the other hand some studies have shown that the deeper portions of vastus lateralis have a greater proportion of type 1 fibers than the surface portions. Therefore, if by chance leaner subjects were biopsied deeper than obese then the data might be biased. The observation of a variation in fiber type proportions throughout vastus lateralis has not been consistently demonstrated however, so it is questionable how much this variation could have affected our data $(28,42-44)$. Vastus intermedius may have more type 1 fibers than vastus lateralis but an inadvertant biopsy of this muscle would seem to be unlikely and rare. A relationship of fiber type to obesity and insulin action should certainly be confirmed by other human studies.

Capillary density and insulin action. Oxidative capacity of skeletal muscle is associated with the presence of a specific pattern of muscle cell enzyme activities and an increased supply of capillaries $(27,28,33,34,45,46)$. Hence correlations with capillary density might reflect either correlations with cellular biochemical changes or correlations directly related to the increased distance between capillaries and a greater area of cell membrane served

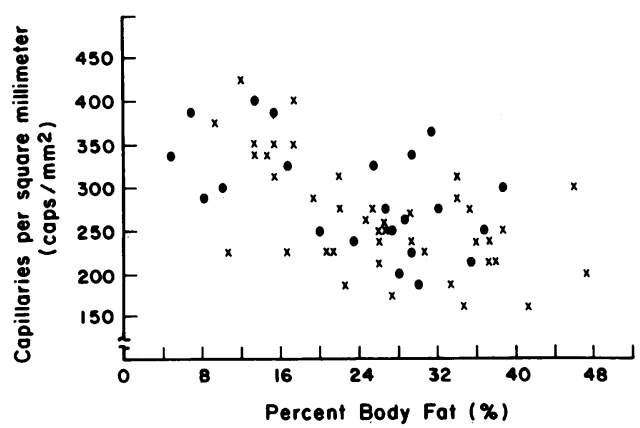

Figure 7. Relationship of capillary density and degree of obesity (percent fat) $(r=-0.59, P \leq 0.0001)$. ( $x$ ) Indians; (๑) Caucasians. by each capillary. Tyrosine kinase activity of the insulin receptor has been correlated with muscle fiber type (31). Because oxidative capacity and capillary density are greater with type 1 fibers, it is possible that the tyrosine kinase activity might correlate with greater oxidative capacity of fibers, though this remains to be directly tested. No studies have directly tested whether other biochemical changes that influence insulin action are also associated with changes in oxidative capacity of muscle cells.

Removal of insulin or glucose from the plasma is regulated by flow through the capillaries and the ability of the substance to diffuse into the tissues $(47,48)$. James et al. (49) recently showed that blood flow to skeletal muscle was not a determinant of glucose disposal indicating that diffusion was the limiting factor. Indeed, low extraction ratios are themselves an indication that diffusion and not blood flow is limiting tissue uptake of substrate $(47,48)$. Studies during oral glucose loading in man have shown modest arterio-venous differences for glucose and insulin, indicating that diffusion from the capillaries may be important (50). Under most physiological conditions the major diffusion barrier to glucose uptake into muscle must be the mus-

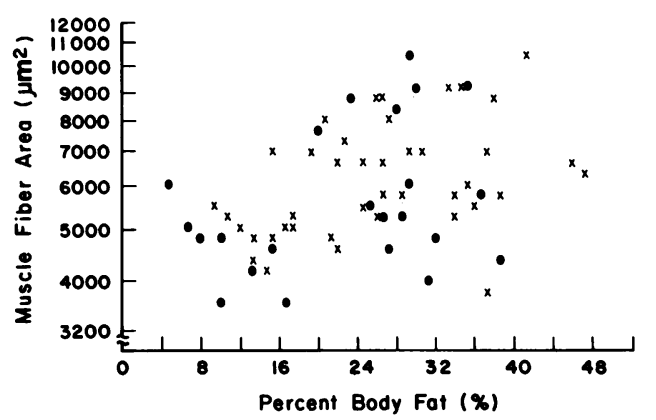

Figure 8. Relationship of muscle fiber cross-sectional area and degree of obesity $(r=0.39, P<0.002)$. ( $x$ ) Indians; $(\bullet)$ Caucasians. 


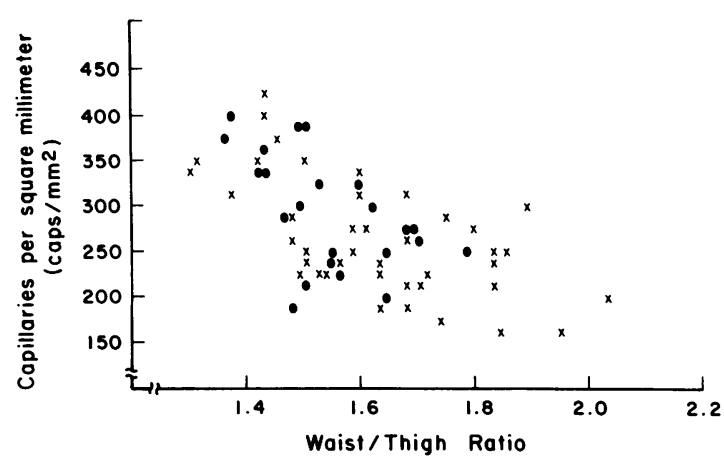

Figure 9. Relationship of capillary density and W/T $(r=-0.60, P$ $\leq 0.0001)$. $(x)$ Indians; $(\bullet)$ Caucasians.

cle cell membrane. To insulin however, the nonfenestrated (51) capillaries of skeletal muscle provide a significant diffusion barrier $(48,52-55)$ inspite of active transport through the capillary wall (56). Furthermore the space between muscle cells may be very narrow $(0.1 \mu \mathrm{m})(57)$ and could further reduce insulin's diffusion to the parts of the cell membrane most distance to the capillary. ${ }^{2}$ If such diffusion barriers do exist then those subjects with the largest tissue volume depending on each capillary may have the lowest average interfiber insulin concentrations and the worst insulin action. We suggest that the correlations of insulin action with capillary density could reflect some such mechanism, but confirmation of this will await more direct studies. The correlation of $\max M$ with capillary density was weaker than submax $M$ and was in fact not present independent of $W / T$. We have already noted that the correlation could be due to as yet unknown biochemical changes associated with changes in oxidative capacity. Alternatively, it is possible that when insulin action is maximal and glucose uptake potentially very rapid, the rate of diffusion of glucose down the narrow intracellular cleft or even across the unfenestrated capillary walls could have reduced glucose uptake in those with low capillary density.

In the basal state the lymphatic insulin appears to be lower than the arterial insulin concentration (52). Because lymphatics do not drain deep between muscle fibers $(22,23,58)$, it is possible that with reduced capillary density there is even a further reduction in insulin at those portions of the muscle cell with least access to a capillary. The correlations of fasting glucose and insulin with capillary density suggest that some direct or indirect factor associated with capillary density must be having an effect on basal glucose homeostasis.

The relationship of insulin action and capillary density could explain several interesting observations in the literature. Prager et al. (39) noted that at low insulin infusion rates there was delayed activation of glucose uptake in obese subjects and this delay was eliminated at very high insulin concentrations. Doedem et al. (40) noted both a defect in the rate of response to insulin and the amplitude of response in the obese, and noted that the defect in insulin action in the obese was greater during changing insulin levels. These effects are predicted by the results of our studies, because increased diffusion distances with decreased capillary density in obese subjects would require greater

2. The concept of insulin or glucose gradients is an extension of cylindrical geometry models for oxygen diffusion first suggested by Krogh (21). We are indebted to Dr. T. W. Secomb, Department of Physiology, University of Arizona, Tucson, for his advice about capillary biophysics.

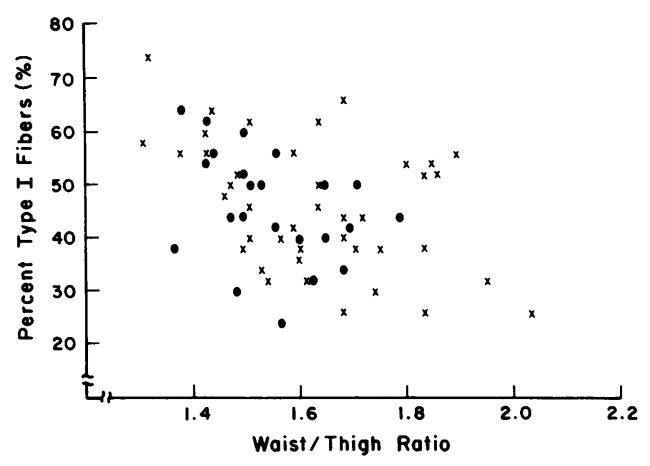

Figure 10. Relationship of percent type 1 muscle fibers in musculus vastus lateralis and W/T $(r=-0.39, P<0.002)$. ( $\times$ ) Indians; ( $\bullet$ Caucasians.

time for insulin concentrations to reach a new equilibrium around the muscle cells. Time taken to diffuse increases with the square of the diffusion distances (48).

Muscle fiber type and insulin action. Structural differences between the light chains of myosin ATP-ase result in differences in the contractile speed (twitch) of myofibrils and the histochemical staining of the cells that contain them $(28,59)$. All human muscles are of mixed fiber type (44) but there appears to be real differences in the proportions of particular muscle fibers between individuals $(28,44)$. While there is probably not total agreement, it appears that the proportions of type 1 muscle fibers may be genetically determined and relatively fixed, but that interchange may occur between the subtypes $2 \mathrm{~A}$ and $2 \mathrm{~B}$ $(28,33-35)$. In in vivo animal studies, slow twitch and fast twitch oxidative fibers (types 1 and 2a) (27) have the greatest insulin sensitivity and probably responsiveness, and fast twitch glycolytic fibers (type 2B) have the least $(29,30,32)$. However, it is not yet known with certainty what determines the insulin sensitivity of a particular fiber type. We have found a positive correlation between insulin action and the percentage of type 1, and a negative correlation with the percentage of type $2 \mathrm{~B}$ fibers in vastus lateralis, as might have been predicted on the basis of animal studies.

In vivo insulin action and skeletal muscle morphology: implications for the clinical correlates of insulin resistance. A genetic component to insulin resistance is suggested by the recent observation that in vivo insulin action independent of degree of obesity is a familial characteristic (36). The familial dependence of insulin action is even stronger if obesity is not adjusted for because obesity is itself familial (60). Other studies (35) suggest

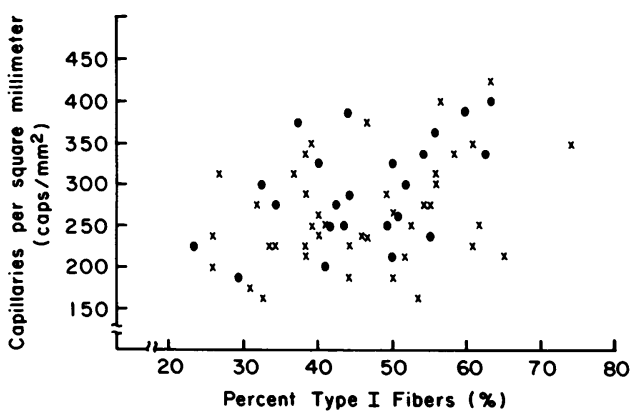

Figure 11. Relationship of percent type 1 muscle fibers and capillary density $(r=0.39, P<0.002)$. ( $\times$ ) Indians; ( $\bullet$ Caucasians. 
that muscle fiber types are genetically determined. In light of the current findings, it is therefore possible that the familial basis of insulin action is due to inherited proportions of particular fiber types. Insulin action and fiber types were not correlated independently of percent fat. This might partially be explained by the fact that it is more difficult to get a representative sample of muscle than to measure obesity. The relationship of fiber type and obesity could mean that insulin resistance from altered muscle fiber type is linked in some way to the cause of the obesity and that we cannot detect any additional relationship of $M$ value and fiber type because of the lack of precision of our tests.

Obesity is associated with increases in FFM (61) and visceral cell sizes (62). This increase in FFM is by definition independent of any triglyceride accumulation in cells. Because muscle cells do not multiply (63), their size must also increase with the increase in FFM (6). We found that capillaries per muscle fiber, however, did not increase with obesity and hence there was a negative correlation of capillary density and percent fat. This finding in obesity is not unlike what happens to the capillary density in weight/power lifters (64). The relationship of capillary density to obesity was, however, much stronger than that of fiber area to obesity so that factors in addition to muscle cell size may be regulating the reduction in capillary density in the obese. The regression analyses suggested that while obesity and capillary density are related they both may have additional independent effects on insulin action.

Fiber type was correlated with both percent fat and W/T. The simple and multiple regression analyses showed that all of the relationship between fiber type and obesity could be predicted from $\mathrm{W} / \mathrm{T}$ alone. It is possible, therefore, that the association of fiber type and obesity is due to an association of increased central adiposity and obesity. The relationship of fiber type and central obesity, which others have also noted (26), might suggest that fiber type and fat distribution are both parts of a more generalized syndrome producing insulin resistance and abnormal glucose tolerance (41).

We noted a rise in glucose concentration over the range of obesity consistent with the correlation of obesity and capillary density, and capillary density and fasting glucose. While this increase is small, the possibility should be considered that such increases may initiate a vicious cycle of hyperglycemia, pancreatic refractoriness to glucose, and further hyperglycemia (6567). If such were the case, it might help to explain the effect of duration of obesity on the incidence of diabetes (68).

In summary, we have found in vivo insulin action to be significantly correlated with capillary density and the proportions of muscle fiber types in musculus vastus lateralis. We postulate that the association of insulin action and capillary density reflects the effect of either some yet to be determined biochemical changes (perhaps associated with alterations in muscle cell oxidative capacity) on insulin action or the effect of diffusion barriers that limit the access of insulin and perhaps glucose to some parts of the muscle cell wall. These diffusion effects are relatively greater when capillary density is reduced, such as in obesity. Therefore this data may provide a partial explanation of insulin resistance in the obese. It may also provide an explanation for slower response time of insulin action in obese subjects, because increased diffusion distances imply a longer time for tissue insulin and glucose concentrations to reach new steady states. The significant association of muscle fiber type and insulin action could be explained by biochemical differences in different types of muscle fibers and/or associated effects of changes in capillary density. The correlation of $\mathrm{W} / \mathrm{T}$ with fiber type may suggest that a central distribution of obesity is part of a more generalized syndrome. The association of muscle fiber type and insulin action might explain the familial dependence of insulin resistance, because fiber type appears to be genetically determined.

Future work is needed to determine if human type 1, 2A, and $2 \mathrm{~B}$ muscle fiber differ in insulin sensitivity and responsiveness as they do in animals, and whether these are related to muscle oxidative function or twitch characteristics. And finally, more understanding is needed of the biophysical properties of skeletal muscle that influence glucose and insulin diffusion.

\section{Acknowledgments}

We gratefully acknowledge the continued support of Dr. Barbara Howard during these studies and her help during preparation of the manuscript, the help of Ms. Carol Lamkin, head nurse of the Clinical Research Unit, the work of Ms. Vicky Boyce and the dietary staff, the supply of insulin by Mr. James Smart of Nordisk USA, Bethesda, MD, the secretarial assistance of Susan Elson and Charlesetta Lincoln, the technical and nursing assistance of Thomas Anderson, John Brown, Aileen Coyne, Revina Frank, Margie Goldsmith, Christina Hendricks, Donna JuddPaddilo, Suzi Moser, Pat Moulsoff, Harlan Osife, Victoria Ossowski, Vera Rodriquez, Donna Rush, Karen Stone, Phyllis Simmons, Pam Thuillez, Dorothy Willer, and Debbie Wolfe-Lopez, the assistance of Sonja Antone, Ramona Ruiz, and the NIH workers in the Gila Indian River Community, and the help and cooperation of residents and leaders of the Gila River Indian Community.

\section{References}

1. Lillioja, S., D. M. Mott, J. K. Zawadzki, A. A. Young, W. G. Abbott, and C. Bogardus. 1986. Glucose storage is a major determinant of in vivo "insulin resistance" in subjects with normal glucose tolerance. J. Clin. Endocrinol. Metab. 62:922-927.

2. Bogardus, C., S. Lillioja, B. V. Howard, G. Reaven, and D. Mott. 1984. Relationship between insulin secretion, insulin action, and fasting plasma glucose concentration in nondiabetic and noninsulin dependent diabetic subjects. J. Clin. Invest. 74:1238-1246.

3. Golay, A., Y.-D. I. Chen, and G. M. Reaven. 1986. Effect of differences in glucose tolerance on insulin's ability to regulate carbohydrate and free fatty acid metabolism in obese individuals. J. Clin. Endocrinol. Metab. 62:1081-1088.

4. Katz, L. D., M. G. Glickman, S. Rapport, E. Ferannini, and R. A. Defronzo. 1983. Splanchnic and peripheral disposal of oral glucose in man. Diabetes. 32:675-679.

5. DeFronzo, R. A., E. Jacot, E. Jequier, E. Maeder, J. Wahren, and J. P. Felber. 1981. The effect of insulin on the disposal of intravenous glucose: results from indirect calorimetry and hepatic and femoral venous catheterization. Diabetes. 30:1000-1007.

6. Lithell, H., F. Lindgarde, K. Hellsing, G. Lundquist, E. Nygarrd, B. Vessby, and B. Saltin. 1981. Body weight, skeletal muscle morphology and enzyme activities in relation to fasting serum insulin concentration and glucose tolerance in 48-year-old men. Diabetes. 30:19-25.

7. Lindgarde, E., K.-F. Erickson, H. Lithell, and B. Saltin. 1982. Coupling between dietary changes, reduced body weight, muscle fiber size and improved glucose tolerance in middle-aged men with impaired glucose tolerance. Acta Med. Scand. 212:99-106.

8. National Diabetes Data Group. 1979. Classification and diagnosis of diabetes mellitus and other categories of glucose intolerance. Diabetes. 38:1039-1057.

9. Goldman, R. F., and E. R. Buskirk. 1961. A method of underwater weighing and the determination of body density. In Techniques for Measuring Body Composition. J. Brozek and A. Hershel, editors. National Academy of Sciences National Research Council Washington, D.C. 78106.

10. Keys, A., and J. Brozek. 1953. Body fat in adult man. Physiol. Rev. 33:245-325. 
11. DeFronzo, R. A., J. D. Tobin, and R. Andres. 1979. Glucose clamp technique: a method for quantifying insulin secretion and resistance. Am. J. Physiol. 237:E214-E223.

12. Steele, R. 1959. Influences of glucose loading and of injected insulin on hepatic glucose output. Ann. NY Acad. Sci. 82:420-430.

13. Meistas, M. T., S. Margolis, and A. A. Kowarski. 1983. Hyperinsulinemia of obesity is due to decreased clearance of insulin. Am. J. Physiol. 245:E155-159.

14. Rossell, R., R. Gomis, R. Casamitjana, R. Segura, E. Wilardell, and F. Rivera. 1982. Reduced hepatic insulin extration in obesity: relationship with plasma insulin levels. J. Clin. Endocrinol. Metab. 56: 608-611.

15. Shephard, R. J., C. Allen, A. J. S. Benode, C. T. M. Davies, P. E. DiPrampero, R. Hedman, J. E. Marriman, K. Mylire, and R. Simmons. 1968. The maximum oxygen uptake. WHO Chron. 38:757-784.

16. Astrand, P. O., and K. Randdahl. 1970. Physiological basis of exercise. In Textbook of Work Physiology. McGraw-Hill, Inc., New York. 291-365.

17. Herbert, V., K. Lau, C. W. Gottlieb, and S. J. Bleicher. 1965. Coated charcoal immunoassay of insulin. J. Clin. Endocrinol. Metab. 25:1375-1384.

18. Yalow, R. S., and S. A. Berson. 1960. Immunoassay of endogenous plasma insulin in man. J. Clin. Invest. 39:1157-1167.

19. Best, J. D., J. G. Judzewitsch, M. A. Pfeifer, J. C. Beard, J. B. Halter, and D. Porte, Jr. 1982. The effect of chronic sulfonylurea therapy on hepatic glucose production in non-insulin dependent diabetes. Diabetes. 31:333-338.

20. Andersen, P. 1975. Capillary density in skeletal muscle of man. Acta Physiol. Scand. 95:203-205.

21. Krogh, A. 1919. The number and distribution of capillaries in muscle with calculation of the oxygen pressure head necessary for supplying the tissue. J. Physiol. 52:409-415.

22. Ham, A. W., and D. M. Cormack. 1979. Histology. 8th ed. J. B. Lippincott Co., Philadelphia.

23. Gould, R. P. 1973. The microanatomy of muscle. In The Structure and Function of Muscle. Vol. 2, part 2. G. H. Bourne, editor. Academic Press, New York. 186-237.

24. Padykula, H. A., and E. Herman. 1955. The specificity of the histochemical method for adenosine triphosphatase. J. Histochem. Cytochem. 3:170-183.

25. Dubowitz, V., and M. H. Brooke. 1973. Muscle Biopsy: A Modern Approach. W. B. Saunders Co., London.

26. Krotkieski, M. 1983. Physical training in the prophylaxis and treatment of obesity, hypertension and diabetes. Scand. J. Rehabil. Med. 15:55-70.

27. Eisenburg, B. R. 1983. Quantitative ultrastructure of mammalian skeletal muscle. In Handbook of Physiology: Skeletal Muscle. L. D. Peachey, editor. Williams and Wilkins, Baltimore, MD. 73-111.

28. Saltin, B., and P. D. Gollnick. 1983. Skeletal muscle adaptability: significance for metabolism and performance. In Handbook of Physiology: Skeletal Muscle. L. D. Peachey, editor. Williams and Wilkins, Baltimore, MD. 555-631.

29. James, D. E., A. B. Jenkin, and E. W. Kraegen. 1985. Heterogeneity of insulin action in individual muscles in vivo: euglycemic clamp studies in rats. Am. J. Physiol. 248:E567-E574.

30. Hom, F. G., and C. J. Goodner. 1984. Insulin dose-response characteristics among individual muscle and adipose tissues measured in the rat in vivo with 3H2-deoxyglucose. Diabetes. 33:153-159.

31. James, D., A. Zorzano, M. Boni, P. Pilch, and N. Ruderman. 1986. Heterogeneity of insulin receptor kinase activity in skeletal muscle of different fiber composition. Diabetes. 34:8A. (Abstr.)

32. Richter, E. A., L. P. Garetto, M. N. Goodman, and N. B. Ruderman. 1984. Enhanced muscle glucose metabolism after exercise: modulation by local factors. Am. J. Physiol. 246:E476-E482.

33. Ingjer, F. 1979. Effects of endurance training on muscle fibre ATP-ase activity, capillary supply and mitochondrial content in man. J. Physiol. (Lond.). 294:419-432.
34. Andersen, P., and J. Henriksson. 1977. Capillary supply of the quadriceps femoris muscle of man: adaptive response to exercise. $J$. Physiol. (Lond.) 270:677-690.

35. Komi, P. V., J. H. T. Viitasalo, M. Havu, A. Thorstensson, B. Sjodin, and J. Karlsson. 1977. Skeletal muscle fibers and muscle enzyme activities in monozygous and dizygous twins of both sexes. Acta Physiol. Scand. 100:385-392.

36. Lillioja, S., D. Mott, W. Knowler, P. Bennett, P. Moll, and C. Bogardus. 1986. In vivo insulin but not secretion is a familial trait. $\mathrm{Di}$ abetes. 35:147A. (Abstr.)

37. Bogardus, C., S. Lillioja, D. M. Mott, C. Hollenbeck, and G. Reaven. 1985. Relationship between degree of obesity and in vivo insulin action in man. Am. J. Physiol. 248:E286-E291.

38. Bogardus, C., S. Lillioja, D. Mott, G. R. Reaven, A. Kashiwagi, and J. E. Foley. 1984. Relationship between obesity and maximal insulinstimulated glucose uptake in vivo and in vitro in Pima Indians. J. Clin. Invest. 73:800-805.

39. Prager, R., P. Wallace, and J. M. Olefsky. In vivo kinetics of insulin action on peripheral glucose disposal and hepatic glucose output in normal and obese subjects. J. Clin. Invest. 78:472-481.

40. Doeden, B., and R. Rizza. 1986. Physiologic assessment of insulin resistance in obesity: defects in both the kinetics and amplitude of response. Clin. Res. 34:543A. (Abstr.)

41. Evans, D. J., R. Murray, and A. H. Kissebah. 1984. Relationship between skeletal muscle insulin resistance, insulin-mediated glucose disposal, and insulin binding: effects of obesity and body fat topography. J. Clin. Invest. 74:1515-1525.

42. Mahon, M., A. Toman, T. T. L. William, and K. M. Bagnall. 1984. Variability of histochemical and morphometric data from needle biopsy specimens of human quadriceps femoris muscle. J. Neurol. Sci. 63:85-100.

43. Edgerton, V. R., J. L. Smith, and D. R. Simpson. 1975. Muscle fiber type populations of human leg muscles. Histochem. J. 7:259-266.

44. Johnson, M. A., J. Polgar, D. Weightman, and D. Appleton. 1973. Data on the distribution of fiber types in thirty-six human muscles. An autopsy study. J. Neurol. Sci. 18:11-129.

45. Peter, J. B., R. J. Barnard, V. R. Edgerton, C. A. Gillespie, and K. E. Stempel. 1972. Metabolic profiles of three fibre types of skeletal muscle in guinea pigs and rabbits. Biochemistry. 11:2627-2633.

46. Lowry, C. V., J. S. Kimmey, S. Felder, M. M.-Y. Chi, K. K. Kaiser, P. N. Passonneau, K. A. Kirk, and O. H. Lowry. 1978. Enzyme patterns in single human muscle fibers. J. Biol. Chem. 253:8269-8277.

47. Michel, C. C. 1972. Flows across the capillary wall. In Cardiovascular Fluid Dynamics. D. H. Bergel, editor. Academic Press, London. 241-298.

48. Caro, C. G., T. J. Pedley, R. C. Schroter, and W. A. Seed. 1978. The mechanics of the circulation. Oxford University Press, Oxford, England. 130-148, 350-433.

49. James, D. E., K. M. Burleigh, C. H. Storlien, S. P. Bennett, and E. W. Kraegenl. 1986. Heterogeneity of insulin action in muscle: influence of blood flow. Am. J. Physiol. 251:E422-E430.

50. Jackson, R. A., N. Peters, U. Advani, G. Perry, J. Rogers, W. H. Brough, and T. R. E. Pilkington. 1973. Forearm glucose uptake during the oral glucose tolerance test in normal subjects. Diabetes. 22:442-458.

51. Junqueir, L. C., and J. Carneiro. 1983. Basic Histology. 4th edition. Lange Medical Publications, Los Altos, CA. 245.

52. Rasio, E. 1982. The capillary barrier to circulating insulin. Diabetes Care. 5:158-161.

53. Rasio, E. A., E. Mack, R. H. Egdahl, and M. G. Herrera. 1968. Passage of insulin and insulin across vascular membranes in the dog. Diabetes. 17:668-672.

54. Rasio, E. A. 1969. The displacement of insulin from blood capillaries. Diabetologia. 5:416-419.

55. Sonksen, P. H., J. R. McCormick, R. H. Egdahl, and J. S. Soeldner. 1971. Distribution and binding of insulin in the dog hindlimb. Am. J. Physiol. 221:1672-1680.

56. King, G. L., and S. M. Johnson. 1985. Receptor-mediated trans- 
port of insulin across endothelial cells. Science (Wash. DC). 227:15831586.

57. Eisenberg, B. R., and I. S. Cohen. 1983. The ultrastructure of the cardiac purkinje strand in the dog: a morphometric analysis. Proc. R. Soc. Lond. B Biol. Sci. B217:191-213.

58. Skalak, T. C., G. W. Schmid-Schonbein, and B. W. Zweifach. 1986. New morphological evidence for a mechanism of lymph formation in skeletal muscle. Microvasc. Res. 28:95-112.

59. Thomason, D. B., K. M. Baldwin, and R. E. Herrick. 1986. Myosin isozyme distribution in rodent lindlimb skeletal muscle. J. Appl. Physiol. 60:1923-1931.

60. Stunkard, J. A., T. I. A. Sorensen, C. Hanis, T. W. Teasdale, R. Chakraborty, W. J. Schull, and F. S. Schulsinger. 1986. An adoption study of human obesity. N. Engl. J. Med. 314:193-198.

61. Forbes, G. B., and S. L. Welle. 1983. Lean body mass in obesity. Int. J. Obesity. 7:99-107.

62. Naeye, R. L., and P. Roode. 1970. The sizes and numbers of cells in visceral organs in human obesity. Am. J. Clin. Pathol. 54:251253.
63. Goldspink, G. 1972. Postembryonic growth and differentiation of striated muscle. In The Structure and Function of Muscle. 2nd ed. Vol. 1, part 1. G. H. Bourne, editor. Academic Press, New York.

64. Tesch, P. A., A. Thorsson, and P. Kaiser. 1984. Muscle capillary supply and fiber type characteristics in weight and power lifters. J. Appl. Physiol. 56:35-38.

65. Bolaffi, J. L., A. Heldt, L. D. Lewis, and G. M. Grodsky. 1986. The third phase of in vitro insulin secretion. Evidence for glucose insensitivity. Diabetes. 35:370-373.

66. Leahy, J. L., H. E. Cooper, D. A. Deal, and G. C. Weir. 1986. Chronic hyperglycemia is associated with impaired glucose influence on insulin secretion. J. Clin. Invest. 77:908-915.

67. Unger, R. H., and S. Grundy. 1985. Hyperglycemia as an inducer as well as a consequence of impaired islet cell function and insulin resistance implications for the management of diabetes. Diabetologia. 28: 119-121.

68. Everhart, J. E., D. J. Pettit, K. R. Slaine, and W. C. Knowler. 1986. Duration of obesity is a risk factor for non-insulin-dependent diabetes (NIDDM). Am. J. Epidemiol. 124:525. (Abstr.) 